\title{
Reading Comprehension Through the Didactic Prism
}

\author{
S.A. Aladeyomi, Ade Adejumo \\ Ladoke Akintola University of Technology, Ogbomoso, Nigeria
}

\begin{abstract}
Reading and comprehension are critical intellectual skills which have to be mastered for any worthwhile academic engagement. However, the tendency to equate mere literacy to these skills has led many people to take the skills for granted. This paper addresses the issue of reading comprehension through a painstaking methodical exploration of the technicalities involved to aid a mastery of the art. It does so with practical examples which are useful for self-teaching on the part of learners.
\end{abstract}

Keywords: reading, comprehension, skills, academics, technicalities

\section{Introduction}

"Reading” and "Comprehension” are two different but related skills that must be taught and learnt in tertiary institutions to facilitate easy flow of knowledge. Writers use language to express their ideas and thoughts in a text. The language they use has certain patterns. The patterns could be in phrases, clauses, sentences, or paragraphs. The way words are arranged in a text assists the reader to understand the information or message being passed across.

Many attempts have been made by language and communication scholars to define or describe "reading". Among many others are Fries (1963), Bright and Mcgragor (1970), Allen and Corder (1975), Abott and Wingard (1985), Smith (1978) and Osisanya (1987). Fries (1963) describes "reading” as the transfer of a physical means of contact of sounds to graphic shapes. Smith (1978) sees it as a process of putting readers in contact with ideas. Abott and Wingard (1985) describe reading as a silent and individual activity, since the writer's expectation was that the text would be read, not heard.

These scholars seem to agree that there are two aspects or levels in describing "reading". First, it is the visual task of decoding the marks on the page the brain and eye having a constant contact. Second, it is the cognitive task - that of interpreting the visual information. This is what Abott and Wingard (1985) describe as thinking skills, since some kind of reconstruction takes place in the reader's mind. The reader attempts to build up the meaning the writer had in mind when he wrote the text.

Banjo and Bisong (1985) define Comprehension on the other hand, as the ability to understand clearly what is being expressed in a text. To comprehend a text therefore depends very much on efficient reading. One has to be able to read efficiently in order to comprehend a piece of information. What a reader should aim at is reading with understanding. This means understanding the main points presented by the writer in the text and being able to relate these ideas to details supporting them.

S.A. Aladeyomi, Ph.D., Department of General Studies, Ladoke Akintola University of Technology. Ade Adejumo, Ph.D., Department of General Studies, Ladoke Akintola University of Technology. 


\section{Getting the Meaning in a Text}

Olasehinde (1999) describs communication as involving the giving and receiving of understanding information, such that the reader of a text is able to respond by appropriate action or inaction. The response given is determined by the reader's understanding of the intention of the writer. The reader should be able to extract the meaning of the text he is reading. To achieve this, Banjo and Bisong (1985) suggest that readers should follow the following steps:

(1) Concentrate on the topic or central theme;

(2) Anticipate what is to follow in the train of thought;

(3) Pick out the main points and try to see the relationship between them;

(4) Decide what the author's attitude is.

In a second language situation, learners are faced with the problems of getting the meaning of the reading passage. Black (1961) summarizes some of these problems as follows:

(1) The inability of the learners to understand a writer's intention and deals;

(2) The inability to detect ironies, allusions, in other words figures of speech in a given text;

(3) More importantly, the inability of the learners to add to the text a meaning that is not in it.

These problems are traceable to the fact that majority of second language learners of the English language do not have adequate linguistic skills in facing a given passage. In other words, they are not able to understand complex linguistic structures. Therefore, it is suggested that a learners should first be well grounded in grammar and should acquire adequate vocabulary to face the task of reading comprehension.

\section{Recognizing Structural Clues}

Meanings can be located in different parts of a sentence. To extract such meanings from a given passage, the reader must understand the structural patterns of each sentence in the passage. These include the subject, the verb, the object, and the adverbial. The subject and the object which belong to the nominal group are usually nouns and pronominals. They usually identify or indicate the participants in the sentences, for example,

(1) Olu is a boy.

The sentence indicates that "Olu” not "Ayo" is a boy. "Olu” is the subject of discussion. It is Olu not Ayo that talked about.

(2) I worked very hard.

"I" is a personal pronoun. It is the subject of discussion. "I" occupies the subject area.

(3) The handsome boy is John.

"The handsome boy" is a phrase that occupies the subject area. It is "the handsome boy" that is talked about or discussed.

(4) What cannot be cured must be endured.

"What cannot be cured" is what is talked about. It is the subject of discussion. It is noun clause that functions as a subject.

Meanings can also be located in the verbal element. This part indicates the acts or actions performed in the sentence, for example:

(5) The boy ran home.

In the sentence above, the action performed is indicated by the verb "ran". This pins down the action to a 
contextualized meaning and immediately marks it out as distinct from other actions like "walking”, "jumping” etc., which are possible activities to be embarked upon by the subject in other context.

Meanings are also carried by the adverbial elements in a sentence. These meanings include the means, modes, and processes of the activities involved. An example is;

(6) He walked slowly.

"Slowly" here shows the manner in which the walking of the participant is done and contrasts it immediately as words like quickly, briskly etc..

\section{Identifying the Main Idea}

A paragraph is usually developed around a major point. The point could be stated in the first sentence, and the rest of the paragraph amplifies, or supports it. A paragraph constructed this way is called a loose paragraph .

For example, fortune is nor the reward of those who leave their affairs to luck and idle away their time. It crowns the efforts of those who apply themselves to their duty with courage, without being afraid of hard work. "Nothing Ventured, Nothing gained" is as true as the sleeping fox catches no poultry. It is idle to curse our fate instead of exerting ourselves to win the great and good things of the world. Nothing is denied to a man who sets about his best energies, undaunted by the obstacles that may stand in his way.

In the passage above, the first sentence carries the main idea in the paragraph while other sentences merely support the main ideal. These points are explained below:

(1) Main idea: Fortune is not the reward of those who leave their affairs to luck and idle away their time.

Proposition: Fortune does not come as a result of luck or laziness

(2) Supporting detail: It crowns the efforts of those who apply themselves to their duty with courage, without being afraid of hard work

(3) Supporting detail: "Nothing Venture, nothing gained" is as true as the sleeping fox catches no poultry.

Proposition: No success is achieved without expense.

(4) Supporting detail: It is idle to curse our fate instead of exerting ourselves to win the great and good things of the world.

(5) Supporting detail: Nothing is denied to a man who sets about his best energies, undaunted by the obstacles that may stand in his way.

Proposition: Complete success goes to the man who strives against all odds.

Very rarely, the writer may delay by keeping the readers waiting, while making a number of points, till the end of find out what they are being led to know. In the last sentence, the writer will state the topic/subject that he has been illustrating or preparing for. Therefore, when a topic sentence is presented as the last sentence of a paragraph, it is called a periodic paragraph.

They therefore brought him out to do with him according to their law; and first, they scourged him, then they buffeted him, then they lanced his flesh with knives; after that they stoned him with stones; then pricked him with their swords and last of all, they burned him to ashes as the stake. Thus came faithful to his end.

Main points: Thus came faithful to his end.

Proposition: Faithful was murdered

Supporting detail: They therefore brought him out to do with him according to their law; and first, they scourged him, then they buffeted him, then they lanced his flesh with knives; after that they stoned him with stones; then pricked him stoned him with stones; then pricked him with their swords and last of all, they burned 
him to ashes at the stake.

Supporting detail:

(1) They dealt with him in line with their law.

(2) They molested him and lanced his flesh.

(3) They threw stones at him.

(4) They killed him with sword and burnt him to the grand.

Sometimes, the topic sentence may not be easily known. It may not be vividly stated. In that case, the reader is left alone to infer from the paragraph the central or main idea around which all the sentences revolve.

For example, a few days ago, I was just having my siesta when I heard cries of agony from the nearby street, I jumped out of my bed only to discover that two beautiful girls had been crushed to death by a taxi. The accident was the third of its kind in two weeks, claiming about seven lives in all. About a month ago, three jolly friends had been electrocuted in the same area as a result of an electric pole which fell down after a heavy down pour. All these and other horrible incidents which had occurred in the past made me wonder if man's scientific achievements have not been a curse rather than a blessing. If man is no longer safe in the midst of his inventions, is he not then a slave of his handiwork? Of what value is an achievement which turns round to spell doom to its master? These were some of the questions which, for long, had been agitating my mind. People are dying in thousands all over the world as a result of the hazards of one invention or the other.

\section{Identifying the Denotations and Connotation of Expression}

It is necessary to identify what expressions in the passage(s) denote or connote for comprehension to take place. It may be restated here that denotation is the underline/surface meanings of the expressions; while connotation refers to the deeper meaning of expressions; readers may consider the example below:

It is difficult to achieve very good success in life without going through fire. In the example above, "fire" which denotatively refers to a conflagration has been used connotatively. It goes with such shades of meaning as "a hard time", difficulties", etc..

\section{Identifying Strategies for Developing the Main Idea}

Main ideas are developed by authors through a number of different techniques. If readers are aware of these common techniques they would understand what they read and recognize how the ideas are structured and developed in a given text.

Writers usually develop their ideals by means of definition, repetition, and examples/illustration.

Definition. When a writer feels that he has used a difficult or unfamiliar word in a topic sentence, that might prevent the reader from understanding the ideals presented, he will often include the definition of the words within the sentences.

Repetition. Repetition is another techniques the author uses to clarify or reinforce and the idea he is trying to convert. The authors may have to repeat the ideal in a different manner by choosing the synonyms of the first lexical word for example. The technique or device being used, is crude.

Example and illustration. Very often, authors use examples and illustrations to clarify and expand their ideals. These examples and illustrations could be removed without changing the meaning of the text.

\section{Conclusion}

Thus far, this paper has examined reading comprehension as a vital aspect of textual understanding. It has 
covered types and strategies involved in reading comprehension. It has demonstrated that if the strategies are fully mastered, textual understanding will be enhanced. The strategies are also capable of assisting the learner in summarizing and note making.

\section{References}

Allien, J., \& Corder, S. (1975). Course in applied linguistics. Edinburgy: Oxford University Press.

Bright, J., \& Megregor, G. (1970). Teaching English as a second language. U.K.: Longman.

Greenwood, J. (1985). Comprehension and reading. In A. Gerry, \& W. Peter, (Eds.), English as an international Language: A Practical Guide. London: Collin.

Rivers, W. (1968). Teaching foreign language skills. Chicago: Chicago University Press.

Smith, F. (1978). Reading. Cambridge: Cambridge University Press. 